\title{
First Report of Dactylispa lenta Weise (Coleoptera: Chrysomelidae) as a Vector of Rice Yellow Mottle Virus
}

\author{
O. O. BANWO ${ }^{1}$, R. H. MAKUNDI ${ }^{1}$, \\ R. S. ABDALLAH ${ }^{2}$ and J. C. MBAPILA ${ }^{3}$ \\ ${ }^{1}$ Sokoine University of Agriculture, P.O. Box 3005, Morogoro, Tanzania \\ ${ }^{2}$ Tropical Pesticides Research Institute, P.O. Box 3024, Arusha, Tanzania \\ ${ }^{3}$ Agricultural Training and Research Institute, Private Bag, Ifakara, Tanzania
}

\begin{abstract}
Rice yellow mottle virus (RYMV) is a severe disease of rice in Africa. It is naturally transmitted by several species of beetles. Chaetocnema pulla is widely believed to be an important vector of RYMV in Tanzania. However, the high incidence of RYMV in some rice fields where C. pulla was not seen in large numbers indicated that more vectors of the virus might exist. Transmission studies conducted showed Dactylispa lenta to be a vector of RYMV in Tanzania. This has not been previously known.
\end{abstract}

Keywords: Chaetocnema pulla, Dactylispa lenta, rice yellow mottle virus.

Tanzania is the largest producer and consumer of rice in the East, Central and Southern Africa (ECSA) region after Madagascar. Rice is grown in different ecologies (upland, lowland and irrigated) and the major producing regions are Mbeya, Morogoro, Mwanza and Shinyanga.

Rice yellow mottle virus is specific to Africa and it is concentrated in the eastern and western parts of the continent. It is clearly the most important disease of rice in Tanzania. It has spread fast and now is found in almost all the rice growing regions.

In countries where the disease is prevalent, Chaetocnema spp, Dicladispa spp, Trichispa sericea and Sessilia pussila are reported to be important RYMV vectors and the disease is also mechanically transmissible (Bakker, 1974; Reckhaus and Andriamasintseheno, 1997; Abo, 1998). Out of the above-mentioned vectors only Chaetocnema pulla was encountered in this study. It was observed that in fields where Dactylispa lenta was found and Chaetocnema pulla was not seen in large numbers, the RYMV incidence was usually higher than in fields where Dactylispa lenta was absent. This gave the indication of Dactylispa lenta as a possible vector of RYMV and hence necessitated this study. 


\section{Materials and Methods}

The experiment was conducted in the screenhouse. The mean temperature in the screenhouse was $23{ }^{\circ} \mathrm{C}$ (maximum $31{ }^{\circ} \mathrm{C}$ and minimum $16^{\circ} \mathrm{C}$ ) during the study. Seeds of variety 'Supa' which is susceptible to the disease were used. The insects (Dactylispa lenta) were collected from rice fields in Morogoro and Mbeya regions which are widely known to be 'hotspot' regions for this disease in Tanzania. The insects were collected by the use of aspirators and sweepnet. During transportation from the field, the insects were kept in containers (bottles) closed by a perforated cover with a closable opening. An electronically operated aspirator and camel hairbrush were used to collect and transfer insects from plant to plant and from cage to plant. Wooden cages measuring $70 \mathrm{~cm} \times 80$ $\mathrm{cm} \times 70 \mathrm{~cm}$ were used in keeping the insects before being used for the transmission tests. Another improvised cage as used by Banwo and Harrington (1998) was used to retain insects on virus source plants (acquisition feeding). Cellulose acetate tubes measuring 2.5 $\mathrm{cm}$ with a netting top were used to retain viruliferous insects on test plants (inoculation feeding). Acquisition feeding was for 3 days on potted rice plants inoculated about three weeks earlier. Also, inoculation feeding was for 3 days on potted young rice seedlings at the 2 to 3 leaf stage, transplanted 2 days earlier. Rice plants are more susceptible to the disease at the seedling stage (Bakker, 1974). Adult insects were used in the transmission tests since they are responsible for the dissemination of vectored viruses under most field conditions (Fulton et al., 1987). One insect per test plant was used. The plants were kept in the screenhouse for three weeks for symptom observation. The Enzyme Linked Immunosorbent Assay (ELISA) test as described by Clark and Adams (1977) was conducted in the laboratory to determine which plants were infected. Ten potted plants were used for each of the different vector populations (1, 2, 3 and 4) and the experiment was run/replicated 5 times. The transmission percentage for each of the vector populations was then obtained.

\section{Results and Discussion}

The results of the transmission tests (Fig. 1) clearly show that Dactylispa lenta was able to transmit RYMV to healthy seedlings. The insect caused similar foliage damage typical of beetles on the rice plants. Interestingly however, earlier reports (e.g. Nye, 1960: De-Pury, 1975 and Akhabuhaya and Lodenius, 1988) did not show the presence of Dactylispa lenta on rice in Tanzania. This indicates that the number of important insect species on rice might have increased over the years. Bakker (1974) reported Dactylispa bayoni as a vector of RYMV in Kenya. However, this is the first report of Dactylispa lenta as a vector of RYMV. It confirms reports that pest problems may vary from one area to another in view of the diverse conditions under which rice is grown (Grist and Lever, 1969; Alam, 1984; Heinrichs, 1994).

Unlike Chaetocnema pulla, Dactylispa lenta was not found in all the fields visited hence might be considered to only be potentially an important vector of RYMV in Tanzania. 


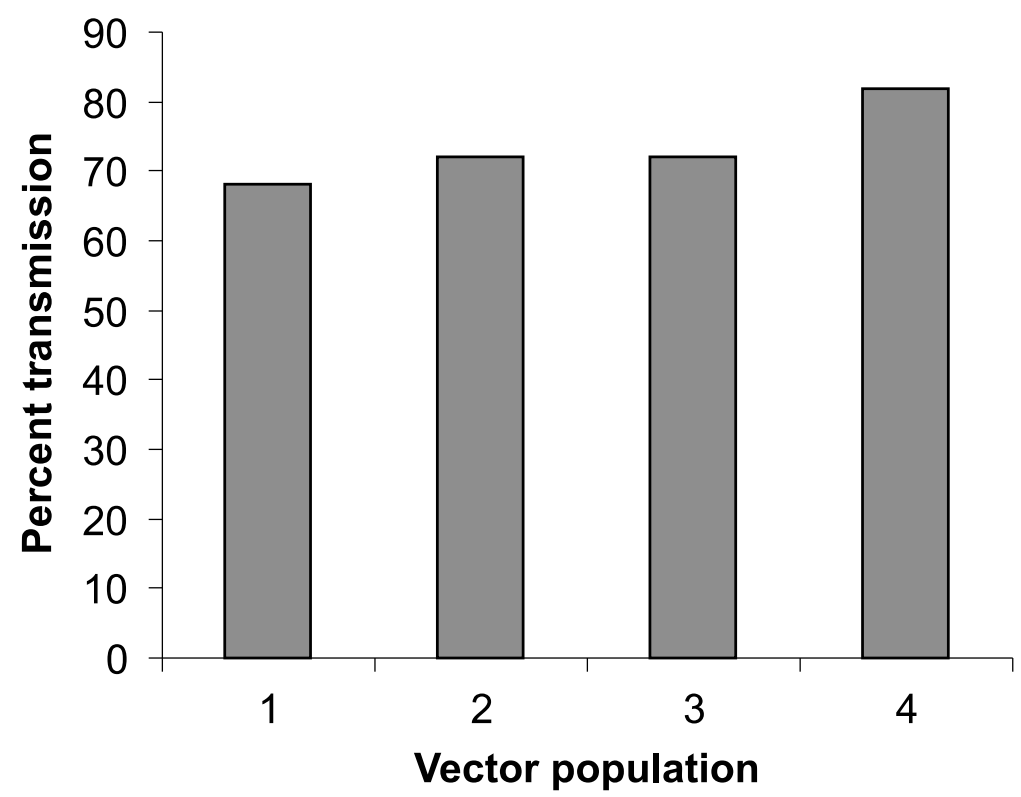

Fig. 1. Transmission of RYMV by Dactylispa lenta (Coleoptera: Chrysomelidae)

\section{Acknowledgements}

The first author is a German DAAD scholar. We are grateful to Dr F. M. Kimmins of the NRI, Chatham, Britain for providing some facilities for this work. Dr. D. Fargette of the CIRAD/IRD, France provided the antiserum. The magnanimity of Drs S. V. Green (also of the NRI) and C. L. Staines (NMNH), Washington, U.S.A in the identification of the insect is gratefully acknowledged.

\section{Literature}

Abo, M. E. (1998): Studies on the mode of transmission of rice yellow mottle virus. Ph. D. Thesis submitted to the Ahmadu Bello University, Zaria, Nigeria. 148 pp.

Akhabuhaya, J. and Lodenius, N. (1988): Pesticides in Tanzania. Publication of the Department of Environmental Conservation, University of Helsinki No 10 Helsinki Press. 128 pp.

Alam, M. S. (1984): Insect Survey. IITA Annual Report, Ibadan, Nigeria. 67 pp.

Bakker, W. (1974): Characterisation and ecological aspects of rice yellow mottle virus in Kenya. Agricultural Research Report. Center for Agricultural Publishing and Documentation, Wageningen. 152 pp.

Banwo, O. O. and Harrington, R. (1998): 'Is resistance to barley yellow dwarf virus in spring barley related to aphid feeding behaviour?' Int. Barley Newsletter 42, 50-54.

Clark, M. F. and Adams, A. N. (1977): Characteristics of the microplate method of enzyme linked immunosorbent assay for the detection of plant viruses. J. Gen. Vir. 34, 475-483

De-Pury, J. M. S. (1975): Crop Pests of East Africa. Oxford University Press, London. 276 pp. 
Fulton, J. P., Gergerich, R. C. and Scott, H. A. (1987): Beetle transmission of plant viruses. Ann. Rev. Phytopath. 25, 111-123.

Grist, D. H. and Lever, R. J. A. W. (1969): Pests of Rice. Longman, London. 520 pp.

Heinrichs, E. A. (1994): Biology and management of rice insects. John Wiley and Sons. 779 pp.

Nye, I. W. B. (1960): The insect pests of graminaceous crops in East Africa. Report of a survey carried out between March 1956 and April 1958. Colon Res. Studies 31, 37.

Reckhaus, P. M and Andriamasintseheno, H. E. (1997): Rice yellow mottle virus in Madagascar and its epidemiology in north west of the island. Z. Pflkr. Pflanz. schutz 104, 289-295. 